\title{
Cauda equina involvement in newly diagnosed myeloma patient
}

\author{
Demet Cekdemir ${ }^{*}$, Nur Soyer ${ }^{1}$, Halil Gulluoglu ${ }^{2}$, Gulgun Yilmaz Ovali ${ }^{4}$ and Mahmut Tobu ${ }^{1}$ \\ ${ }^{1}$ Department of Hematology, Medical Faculty, Ege University, Izmir, Turkey \\ ${ }^{2}$ Department of Neurology, Medical Faculty, Ege University, Izmir, Turkey \\ ${ }^{3}$ Department of Radiology, School of Medicine, Celal Bayar University, Manisa, Turkey
}

\begin{abstract}
Cauda equina syndrome (CES) is a rare complication of Multiple myeloma (MM) that is a clonal plasma cell disorders. We presented a case who newly diagnosed MM which complicated with cauda equina involvement. A 51-year-old woman admitted to our hospital because of weakness and low back pain. Neurological examination demonstrated sphincter dysfunction, decreased Achilles tendon reflexes, frust hemiparesia, reflected CES. Laboratory analysis was revealed anemia, hipergammaglobulinemia and monoclonal peak in the protein electrophoresis. Magnetic resonance imaging (MRI) of the spine showed multiple vertebral compression fractures and marked contrast enhancement of the cauda equina region. The patient was diagnosed MM with bone marrow biopsy. After VAD treatment, MRI showed disappearance of infiltration. Although, there are some case reports with cauda equina involvement in myeloma patient, we could not find any case presenting with CES in newly diagnosed MM. This rare complication should be remembered in myeloma patients who presented symptoms of CES.
\end{abstract}

\section{Introduction}

Multiple myeloma $(\mathrm{MM})$ is a hematological malignancy that is characterized by presence of proliferation of clonal plasma cells which are producing a monoclonal immunoglobulin [1]. Nervous system involvement is an important complication. Cauda equina syndrome (CES) is defined as the constellation of symptoms that includes lowback pain, sciatica, saddle anesthesia, decreased rectal tone and perineal reflexes, bowel and bladder dysfunction, and variable amounts of lower-extremity weakness [2]. There are several causes of this syndrome including trauma, central disc protrusion, hemorrhage, and neoplastic invasion. We presented a case who newly diagnosed MM which complicated with cauda equina involvement.

\section{Case report}

Written informed consent was obtained from the patient.

51-year-old women admitted to our hospital because of weakness and low back pain. Physical examination revealed pallor and low back pain. Neurological examination demonstrated urinary and anal sphincter dysfunction, decreased rectal tone and perineal reflexes, saddle anesthesia, decreased bilateral Achilles tendon reflexes, frust paraparesia, reflected cauda equina syndrome.

Laboratory analysis were anemia (Hb: 9 gr/dL, Hct: 27 $\%)$, elevated erythrocyte sedimentation rate $(68 \mathrm{~mm} / \mathrm{h})$ and hipergammaglobulinemia (globulin $3.7 \mathrm{~g} / \mathrm{dL})$. Serum creatinine $(1.75$ $\mathrm{mg} / \mathrm{dL}$ ), serum calcium (10.9 mg/dL), $\beta 2$-microglobulin (3452 ng/ $\mathrm{ml})$ and $\mathrm{C}$ reactive protein $(5.1 \mathrm{mg} / \mathrm{dL})$ levels are elevated. Serum protein electrophoresis demonstrated monoclonal peak. Serum immunoglobulin G (IgG) and kappa light chain levels were $2282 \mathrm{mg} /$ $\mathrm{dL}$ and $1014 \mathrm{mg} / \mathrm{dL}$, respectively.

Skeletal survey showed multiple lytic lesions and vertebral compression fractures. Bone marrow aspiration smears and trephine biopsy were demonstrated infiltration of atypical plasma cells, reflecting myeloma. The patient diagnosed stage III A IgG- kappa myeloma. Magnetic resonance imaging (MRI) of the spine showed multiple vertebral compression fractures, marked contrast enhancement of lumbar meningeal region and two solid mass of L4-L5 and L5-S1 segment localization (Figure 1). Standard dose of VAD regimen was administered as vincristine $0.4 \mathrm{mg} /$ day D1-4, doxorubicin $9 \mathrm{mg} / \mathrm{m} 2 /$ day D1-4 and dexamethasone $25 \mathrm{mg} / \mathrm{m} 2 /$ day D1-4 and every three weeks interval bisphosphonate treatment was applied. After 2 cycles of VAD treatment, MRI showed disappearance of infiltration and neurologic findings were regressed (Figure 2).

\section{Discussion}

CES is a clinical picture of perineal sensory loss with loss of voluntary control of both anal and urethral sphincter and of sexual responsiveness. Clinical signs accompanying CES may differ in each patient, but the fully developed syndrome is characterized by lowback pain, bilateral sciatica, saddle hypoesthesia or anesthesia, motor weakness of lower extremities, impairment of anal, bulbocavernous, medioplantar and Achilles tendon reflexes bilaterally, rectal and bladder sphincter dysfunction, as well as sexual impotence. CES is not only secondary to disc disease, but also to other spinal canal pathologies as well. The etiologies can be grouped as non- neoplastic compressive

${ }^{*}$ Correspondence to: Demet Cekdemir, MD, Department of Bone Marrow Transplantation, Anadolu Medical Center, Cumhuriyet Mahallesi, 41400, Gebze, Kocaeli, Turkey, Tel: +90 54248487 47; Fax: +90 26265403 06; E-mail: demetcekdemir@yahoo.com.tr

Key words: cauda equina syndrome, myeloma, magnetic resonance imaging

Received: February 22, 2018; Accepted: March 20, 2018; Published: March 23, 2018 

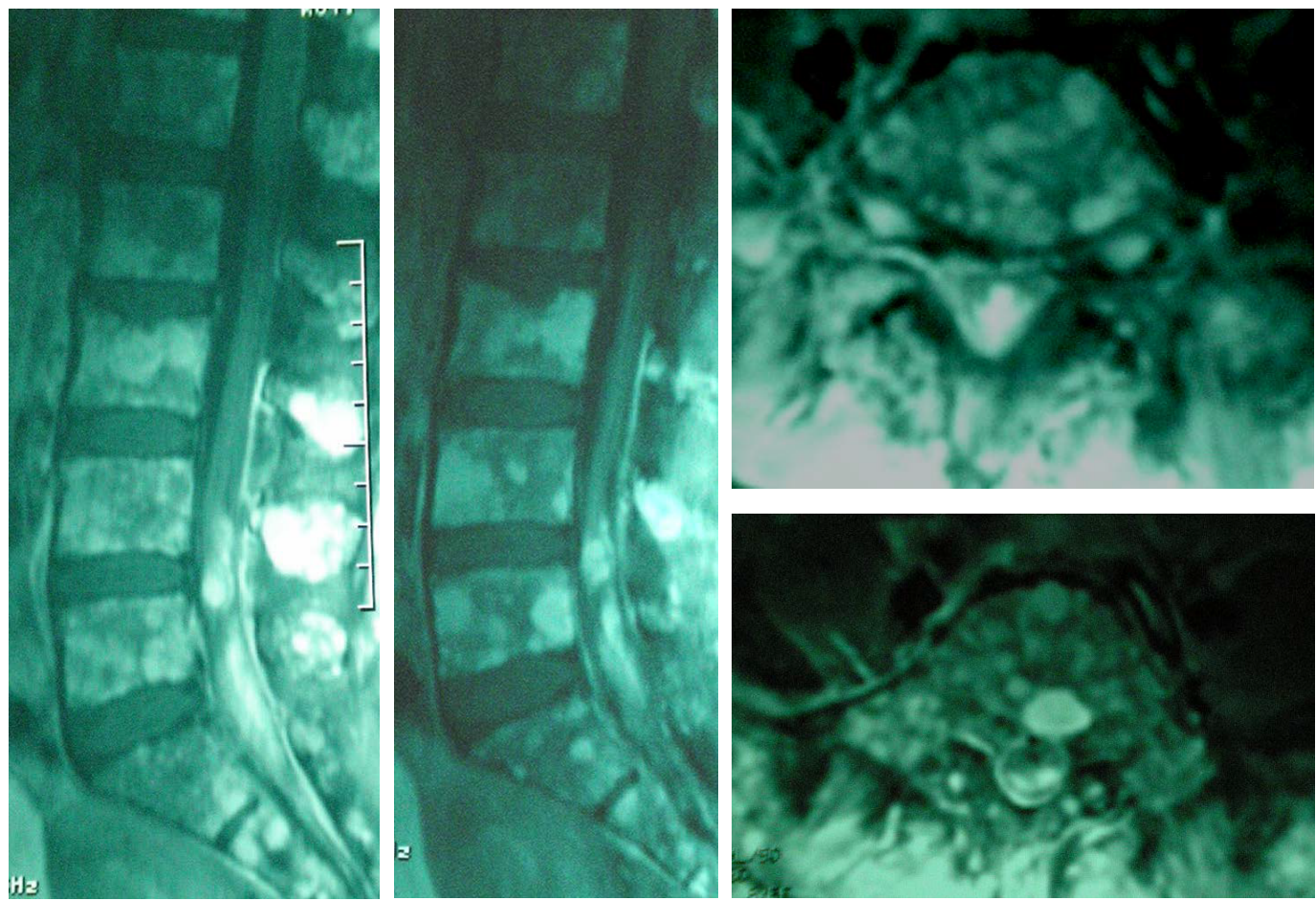

Figure 1. Lumbar sagittal T1-weighted MRI post gadolinium demonstrate marked contrast enhancement of lumbar meningeal region and two solid mass of the cauda equina region (L4-L5 and L5-S1 segment localization).
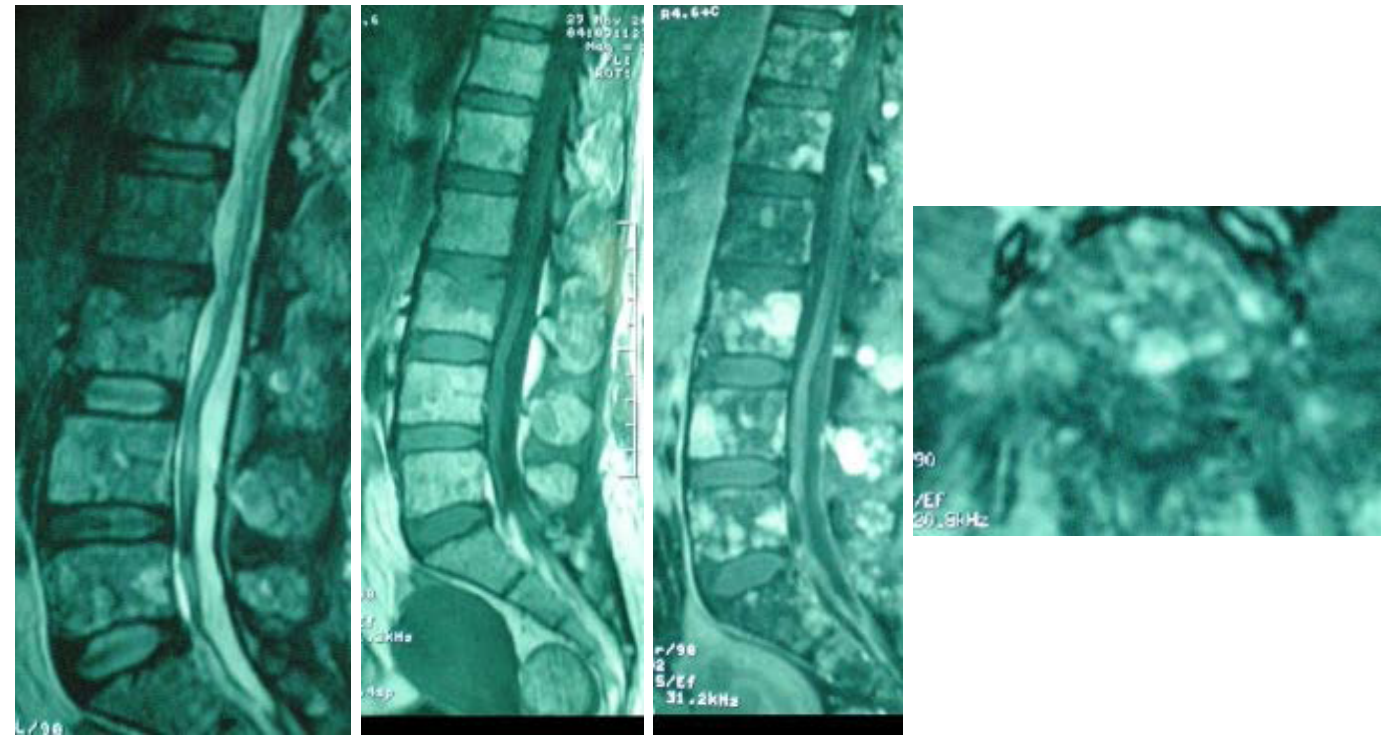

Figure 2. Lumbar sagittal T2-weighted MRI showed disappearance of infiltration.

etiologies, compressive spinal tumors and non-compressive etiologies [3]. Our patient had all of clinical signs of cauda equina syndrome.

MM is a plasma cell disorder that both bone (pathologic fractures, spinal cord compression) and neurologic complications (spinal cord and nerve root compression) are seen in progress of myeloma [4]. But cauda equina involvement is a rare complication.

In the literature, there are some case reports that MM complicated with cauda equina syndrome [5-8]. In a report, a case with MM and sacral insufficiency fracture complicated by epidural hematoma and partial cauda equina compression was presented. In this paper, patient with myeloma in plateau phase had been presented with a short history (less than $12 \mathrm{~h}$ ) of low back pain, parasthesia and lower limb weakness. She had diagnosed sacral insufficiency fracture complicated by epidural hematoma and partial cauda equina compression [5]. In other paper, a case who presenting with cauda equina and cerebrum involvement in myeloma patient after hematologic complete remission had been reported [6]. Another report was described a case who diagnosed cauda equina relapse after autologous stem cell transplantation in a patient with primary plasma cell leukemia [7]. Quint $e t$ al. reported a case with MM who had presented with a 1- week history of progressive bilateral lower extremity pain and weakness [8]. Our patient was presented with $\mathrm{CES}$ and diagnosed MM with cauda equina involvement. 
MRI should be the best initial procedure for patients with suspected CES [2]. Bell et al. recommend emergency MRI be assessed in all patients who present with new onset of urinary symptoms in the context of lumbar back pain or sciatica in order to avoid misdiagnosis or missed diagnosis of CES [9].

A diagnosis of myeloma and CES related to cauda equina involvement of myeloma was made at the same time in our patient. MRI was performed for diagnosis of CES. After chemotherapy for myeloma treatment, all symptoms and radiological findings were disappeared. This rare complication should be remembered in patients with MM who presented low back pain and other neurological symptoms of CES.

\section{Conflicts of interest}

The authors have no financial conflicts of interest.

\section{References}

1. Smith A, Wisloff F, Samson D; UK Myeloma Forum; Nordic Myeloma Study Group British Committee for Standards in Haematology (2006) Guidelines on the diagnosis and management of multiple myeloma 2005. Br J Haematol 132: 410-451. [Crossref]
2. Ma B1, Wu H, Jia LS, Yuan W, Shi GD, et al. (2009) Cauda equina syndrome: a review of clinical progress. Chin Med J (Engl) 122: 1214-1222. [Crossref]

3. Orendácová J, Cízková D, Kafka J, Lukácová N, Marsala M, et al. (2001) Cauda equina syndrome. Prog Neurobiol 64: 613-637. [Crossref]

4. Bladé J, Rosiñol L (2007) Complications of multiple myeloma. Hematol Oncol Clin North Am 21: 1231-1246, xi. [Crossref]

5. Cronin CG, Lohan DG, Swords R, Murray M, Murphy JM, et al. (2007) Sacral insufficiency fracture complicated by epidural haematoma and cauda equina syndrome in a patient with multiple myeloma. Emerg Radiol 14: 425-30. [Crossref]

6. Hayakawa $\mathrm{H}$, Obama K, Tara M (2002) Intradural recurrence of multiple myeloma during the hematological complete remission. Rinsho Ketsueki 43: 1009-13. [Crossref]

7. Okudaira T, Nagasaki A, Miyagi T, Yoshida M, Tamaki K, et al. (2010) Cauda equina relapse after autologous stem cell transplantation in a patient with primary plasma cell leukemia. Gan To Kagaku Ryoho 37: 743-6. [Crossref]

8. Quint DJ, Levy R, Krauss JC (1995) MR of myelomatous meningitis. AJNR Am J Neuroradiol 16: 1316-1317. [Crossref]

9. Bell DA, Collie D, Statham PF (2007) Cauda equina syndrome: what is the correlation between clinical assessment and MRI scanning? Br J Neurosurg 21: 201-3. [Crossref]

Copyright: (C2018 Cekdemir D. This is an open-access article distributed under the terms of the Creative Commons Attribution License, which permits unrestricted use, distribution, and reproduction in any medium, provided the original author and source are credited. 